\title{
Surgical antimicrobial prophylaxis
}

\section{SUMMARY}

Surgical antimicrobial prophylaxis is the most common indication for antimicrobial use in Australian hospitals. However, it is associated with high rates of inappropriate use.

Effective use of antimicrobials to prevent infection is essential to reduce risks associated with surgical procedures. Efforts need to be made to maximise the quality of surgical antimicrobial prophylaxis prescribing.

Procedural prophylaxis (before or during surgery) is not indicated for all surgeries, especially minor procedures. Post-procedural prophylaxis, including the use of topical antimicrobials, is rarely indicated yet frequently prescribed.

The Therapeutic Guidelines: Antibiotic is a key reference for all Australian prescribers.

GPs can have a significant role in optimising surgical antimicrobial prophylaxis and reducing the burden of inappropriate antimicrobial use.

\section{Introduction}

Surgical antimicrobial prophylaxis refers to the use of antibiotics for the prevention of surgical site infections, ${ }^{1}$ and does not include preoperative decolonisation or treatment of established infections. It is the most common indication for antimicrobial use in Australian hospitals. However, $40 \%$ of prescriptions were found to be inappropriate in the 2015 National Antimicrobial Prescribing Survey, which analysed 22021 prescriptions from 281 hospitals. ${ }^{2}$ Inappropriate use, such as extended duration of surgical prophylaxis (e.g. 5 days of cefalexin at discharge), contributes to the overall burden of antibiotic use in the community and exposes patients to adverse reactions and Clostridium difficile infections.

Optimal prescribing in surgical prophylaxis is ideally concordant with the Therapeutic Guidelines: Antibiotic $^{3}$ or local guidelines (as endorsed by the Antimicrobial Stewardship Clinical Care Standard). ${ }^{4}$ Prescribing of prophylaxis occurs in acute and primary care. However, current data on the extent of prescribing in primary care are lacking.

\section{Antimicrobial stewardship}

Antimicrobial stewardship is defined as 'coordinated actions designed to promote and increase the appropriate use of antimicrobials', ${ }^{2}$ and is considered an important strategy for the conservation of the effectiveness of antibiotics. Since 2011, it has been one of the compulsory criteria for hospital accreditation. ${ }^{5}$ Appropriate surgical antimicrobial prophylaxis prescribing is part of the national Antimicrobial Stewardship Clinical Care Standard, which was released in 2014. ${ }^{4}$ This standard was developed for hospital and general practice prescribers and patients. Monitoring antimicrobial use and resistance is a requirement of the National Safety and Quality Health Service Standards. ${ }^{6}$

Significant improvement in prescribing practices (potentially attributable to antimicrobial stewardship programs) in hospitals has been observed by auditing tools such as the National Antimicrobial Prescribing Survey. ${ }^{2}$ Despite identifying surgical antimicrobial prophylaxis prescriptions as a key area of concern, the 2015 Survey found a decline in the proportion of surgical prophylaxis prescriptions extending greater than 24 hours. ${ }^{2}$ Further improvements are still required to meet the best-practice target of less than $5 \%{ }^{2}$

The 2016 Surgical National Antimicrobial Prescribing Survey solely focuses on surgical prophylaxis prescribing. ${ }^{7}$ Its results highlight ongoing concerns regarding inappropriate procedural and postprocedural prescribing ( $43.4 \%$ and $46.5 \%$ respectively) in Australian hospitals. Procedural prophylaxis was defined as any antimicrobial prescribed immediately before or during the surgery, while post-procedural prescribing refers to antimicrobials given after the procedure. Where guidelines were available, $41 \%$ of procedural and $62 \%$ of post-procedural prophylaxis was non-concordant with guidelines (see Table). ${ }^{7}$

\section{Appropriate surgical antimicrobial prophylaxis}

The key elements of appropriate surgical antimicrobial prophylaxis prescribing include the correct indication, antimicrobial, drug dose, route, timing of administration and duration.
Courtney lerano

PhD Fellow

Jo-Anne ManskiNankervis

General practitioner²

Lecturer in primary care ${ }^{2}$

\section{Rod James}

Project officer

Arjun Rajkhowa

Centre manager?

Trisha Peel

Chief investigator

Infectious diseases and antimicrobial stewardship physician ${ }^{3}$

\section{Karin Thursky}

Director

Deputy head ${ }^{4}$

'National Centre for Antimicrobial Stewardship Doherty Institute

Royal Melbourne Hospital/ University of Melbourne

${ }^{2}$ Department of General Practice

University of Melbourne

${ }^{3}$ Department of Infectious Diseases

Alfred Health and Monash University

${ }^{4}$ Department of Infectious Diseases

Peter MacCallum Cancer Centre

Melbourne

\section{Keywords}

antibiotics, antimicrobial prophylaxis, antimicrobial stewardship, drug utilisation, surgery

Aust Prescr 2017:40:225-9 https://doi.org/10.18773/ austprescr.2017.073

First published

14 November 2017 


\section{Table 2016 Surgical National Antimicrobial Prescribing Survey results}

\begin{tabular}{|c|c|c|}
\hline Key assessments & Procedural prophylaxis* & Post-procedural prophylaxis \\
\hline Overall inappropriateness of prescribed antimicrobials & $\begin{array}{l}43.4 \%^{\dagger} \\
(1384 / 3189)\end{array}$ & $\begin{array}{l}46.5 \% \ddagger \\
(1032 / 2218)\end{array}$ \\
\hline $\begin{array}{l}\text { Prescribed antimicrobials non-compliant with } \\
\text { guidelines (where guidelines were available) }\end{array}$ & $\begin{array}{l}41 \%^{\dagger} \\
(1211 / 2954)\end{array}$ & $\begin{array}{l}62 \% \ddagger \\
(894 / 1442)\end{array}$ \\
\hline $\begin{array}{l}\text { Surgical episodes where antimicrobial prophylaxis } \\
\text { was prescribed but not indicated }\end{array}$ & $\begin{array}{l}10.6 \% \\
(281 / 2641)\end{array}$ & $\begin{array}{l}40.3 \% \\
(503 / 1248)\end{array}$ \\
\hline
\end{tabular}

* antimicrobials prescribed immediately before or during the surgical procedure

+ procedural antimicrobials measured in doses

$\ddagger$ post-procedural antimicrobials measured in prescriptions (or courses)

Source: Reference 7

\section{Right indication}

All surgical procedures carry a risk of infection. However, the benefit of prescribing prophylaxis must be balanced against the potential risks of antimicrobial use, including allergic reactions, antibiotic-associated C. difficile and antibiotic resistance.

The 2016 Surgical National Antimicrobial Prescribing Survey found procedural antimicrobial prophylaxis was prescribed but not indicated in $10 \%$ of surgical procedures, and post-procedural prophylaxis was prescribed but not indicated in $40 \%$ of procedures (see Table). ${ }^{7}$

Prophylaxis is not indicated for clean non-prostheticassociated procedures as defined by international guidelines. ${ }^{3,8,9}$ It is more likely to be indicated for procedures where:

- the incidence of surgical site infections tends to be high, for example, colorectal surgery

- the consequences of infection are significant, for example, surgery with implanted material such as arthroplasty and cardiac valve surgery.

Overall, there is insufficient evidence to support surgical prophylaxis for minor procedures, and prophylaxis in general practice is usually not warranted. ${ }^{3,9-11}$ If a patient has an associated infection (e.g. ingrown toenail, or abscess with cellulitis), an appropriate course of antibiotics should be given but this would not be considered prophylaxis. Key practice points for prescribing appropriate surgical antimicrobial prophylaxis in primary care are listed in the Box.

For dental procedures, guidelines recommend that antimicrobial prophylaxis may be appropriate for surgery in immunocompromised patients, and for surgical removal of a bone-impacted tooth or periapical surgery in a patient with a history of recurrent infections. ${ }^{3,8,12}$

\section{Box Best-practice surgical antimicrobial prophylaxis in general practice}

Do not prescribe surgical antimicrobial prophylaxis without an appropriate indication

Avoid topical antimicrobials for surgical procedures Use the eTG for specific information regarding optimal drug, dose, route and timing ${ }^{3}$

Query long-term use of post-procedural antibiotics with the initial prescriber or surgical team

Avoid prescribing ongoing supply of topical and oral antimicrobials without a clear indication from the initial prescriber

Monitor for surgical complications such as superficial, deep and organ space infections, and discuss with the surgeon or treating hospital

The presence of catheters or surgical drains is not an appropriate indication for prolonging surgical prophylaxis. ${ }^{13}$ This use is not supported by current evidence and may increase the risk of adverse events associated with antimicrobial use. ${ }^{8}$

\section{Right antimicrobial}

The choice of antimicrobial is ultimately influenced by the surgical procedure and associated risk factors. It should provide coverage of the expected microbiological flora at the incision site. ${ }^{14}$ This is further influenced by multiple patient-specific risk factors including:

- pre-existing infection

- recent antimicrobial use

- known colonisation with a resistant organism

- prolonged hospitalisation

- prostheses

- weight $^{15-17}$ 
- renal function

- allergy status

- comorbidities

- immunosuppression.

For the majority of procedures, a first-generation cephalosporin, such as cefazolin, remains the preferred antimicrobial for prophylaxis. 3,14,18 Uptake of this recommendation was shown across current Australian practice in the 2016 Surgical National Antimicrobial Prescribing Survey, with cefazolin being the most commonly prescribed antimicrobial for procedural (69\%) and post-procedural prophylaxis (57\%). However, $50 \%$ of the post-procedural cefazolin prescribing was deemed inappropriate. ${ }^{7}$

\section{Right dose}

When indicated, a single defined dose of antibiotic(s), for example, $2 \mathrm{~g}$ intravenous cefazolin, is sufficient for most procedures. ${ }^{3,14}$ This dose may be influenced by patient-related risk factors such as age, renal function and weight. ${ }^{15-17}$

\section{Right route of administration}

Parenteral administration (intravenous or intramuscular) is the preferred route for surgical antimicrobial prophylaxis. However, there are exceptions, including intracameral use for ophthalmic procedures, ${ }^{3,19}$ oral antibiotics for transurethral resections of the prostate ${ }^{3}$ and surgical terminations of pregnancy, ${ }^{3,20}$ and oral amoxicillin before certain dental procedures for endocarditis prophylaxis., 3,12,21

Within the acute setting, the 2016 Surgical National Antimicrobial Prescribing Survey identified intravenous administration as the most common route for procedural (94.2\%) and post-procedural antimicrobials (64.5\%). Oral administration accounted for $20.4 \%$ of post-procedural antimicrobials, however only $18.4 \%$ of oral administrations were deemed appropriate. ${ }^{?}$

\section{Topical prophylaxis}

Overall, there are conflicting data regarding the benefits of topical antimicrobial prophylaxis, ${ }^{22}$ and it is currently not indicated for most wounds, especially those resulting from clean procedures. The most recently updated Centers for Disease Control and Prevention guidelines for the prevention of surgical site infections also advise against the application of topical prophylaxis. ${ }^{8}$ Despite insufficient evidence, antibiotic ointments and creams are frequently used for topical prophylaxis. ${ }^{23}$

Antimicrobial prophylaxis should not be used as a stopgap for inadequate infection prevention measures. Similarly, topical prophylaxis should not be a substitute for good surgical closure technique and dressing management, particularly in cases where wounds are hard to seal and dress.

The most recent Cochrane review proposes that topical prophylaxis 'probably' prevents surgical site infections when compared to antiseptics or no topical antibiotic use. ${ }^{24}$ However, when comparing topical antibiotics to no topical antibiotic use, the number needed to treat for one additional beneficial outcome was 50. It is important to note that this Cochrane review of trials from 1967 to 2014 found a considerably high risk of bias. The authors could not draw conclusions regarding the influence of topical antibiotics on antibiotic resistance and wound healing.

An earlier review on topical prophylaxis in dermatological procedures concluded that there was no significant difference between topical antimicrobials and petrolatum or paraffin for postsurgical wound infections. ${ }^{25}$ An Australian study found that topical chloramphenicol for high-risk suture wounds produced only a moderate absolute reduction in infection rate that was statistically but not clinically significant. ${ }^{26} \mathrm{An}$ earlier Australian randomised controlled trial including 1801 surgical wounds found no significant benefit from mupirocin or paraffin ointments before occlusive dressings when compared to no ointment use. ${ }^{27}$

\section{Antimicrobial resistance}

High use of topical prophylaxis may increase the risk of antimicrobial resistance. A New Zealand study has correlated increasing use of topical fusidic acid with a rapid clonal expansion of fusidic acid-resistant Staphylococcus aureus. ${ }^{28}$

Topical mupirocin is commonly indicated for decolonisation of methicillin-susceptible $S$. aureus (MSSA) and methicillin-resistant S. aureus (MRSA). Increased use has been associated with 'emergence of resistance through enhanced selective pressure and cross-transmission'. ${ }^{29}$ A Korean drug utilisation review found an increase in mupirocin consumption correlated with increases of low- and high-level mupirocin resistance in MRSA infections. ${ }^{30}$

Unrestricted use of mupirocin, in particular for wounds and pressure sores, is strongly associated with increased resistance. ${ }^{29}$ Fortunately, in Australia, mupirocin is a Schedule 4 prescription-only medicine so both GPs and hospital prescribers have a significant role in reducing its inappropriate use.

\section{Right timing of administration}

Appropriate surgical prophylaxis achieves antimicrobial serum and tissue concentrations that exceed the minimum inhibitory concentration for the most probable organisms at the surgical site during the procedure. ${ }^{14}$ Appropriate timing of antimicrobial administration is crucial to prevent effective surgical site infection. 
Incorrect timing of prophylaxis before or during a procedure was the most common factor in inappropriate prescribing in the 2016 Surgical National Antimicrobial Prescribing Survey (45.7\%). ${ }^{7}$

Most guidelines, including Therapeutic Guidelines: Antibiotic, recommend that preoperative intravenous antibiotics be given within 60 minutes of incision. ${ }^{3,8,14,31-34}$ More recently, the World Health Organization recommended administration within 120 minutes of incision. ${ }^{35}$ For caesarean sections, evidence supports antimicrobial prophylaxis before cord clamping rather than afterwards. ${ }^{36,37}$

\section{Right duration}

A single preoperative dose is adequate for the majority of procedures. Post-procedural doses of intravenous antibiotics (up to 24 hours) are only required in defined circumstances, such as some cardiac and vascular surgeries, and lower limb amputation. ${ }^{38-40}$

The 2016 Surgical National Antimicrobial Prescribing Survey found that incorrect duration was the most common factor in inappropriate post-procedural antimicrobial prescribing (73.7\%). ${ }^{7}$ Prophylaxis should not extend beyond 24 hours, regardless of the surgical procedure. Intravenous and oral antibiotic prophylaxis offer no benefit beyond this period. ${ }^{3}$

Post-procedural antimicrobials may be initiated in the acute setting but can be reviewed and re-assessed during follow-up with the GP. It is essential that the surgical team clearly communicates with the GP about post-procedural antimicrobial use (usually in the discharge summary).
A recent retrospective cohort study included 1488 patients who received at least 24 hours of parenteral or oral antibiotic therapy. The study identified $20 \%$ $(n=298)$ of these patients experienced at least one antibiotic-associated adverse event, and 20\% ( $n=56)$ of those adverse events were associated with nonclinically indicated antibiotic regimens. ${ }^{41}$ The authors stated for every 10 additional days of antibiotic therapy, there was a $3 \%$ increased risk of adverse events. ${ }^{41}$

\section{Conclusion}

It is important that all prescribers conserve the usefulness of available antibiotics through the practice of appropriate antimicrobial prescribing. GPs and surgeons play a role in reducing inappropriate surgical antimicrobial prophylaxis by only prescribing prophylaxis when indicated.

Further research into surgical antimicrobial prophylaxis prescribing is warranted to tailor future antimicrobial stewardship interventions for these targeted areas and to ensure that there are appropriate guidelines tailored for general practice that are available at the point of care. $<$

Conflict of interest: none declared

Acknowledgement: Many thanks to Malcolm Clarke (Department of General Practice, University of Melbourne), Lesley Hawes (PhD Scholar, Monash Department of General Practice) and Caroline Marshall (Head of Infection Control, Melbourne Health, and National Centre for Antimicrobial Stewardship chief investigator).

\section{REFERENCES}

1. Munckhof W. Antibiotics for surgical prophylaxis. Aust Prescr 2005;28:38-40. https://doi.org/10.18773/ austprescr.2005.030

2. Australian Commission on Safety and Quality in Health Care. Antimicrobial prescribing practice in Australian hospitals: results of the 2015 National Antimicrobial Prescribing Survey. Sydney: ACSQHC; 2016. https://www.safetyandquality.gov.au/ wp-content/uploads/2017/01/Antimicrobial-prescribingpractice-in-Australian-hospitals-Results-of-the2015-National-Antimicrobial-Prescribing-Survey.pdf [cited 2017 Oct 18]

3. eTG complete [Internet]. Melbourne: Therapeutic Guidelines Limited; 2017. www.tg.org.au [cited 2017 Oct 11]

4. Australian Commission on Safety and Quality in Health Care. Antimicrobial stewardship clinical care standard. Sydney: ACSQHC; 2014. https://www.safetyandquality.gov.au/ publications/antimicrobial-stewardship-clinical-carestandard [cited 2017 Oct 11]

5. McKenzie D, Rawlins M, Del Mar C. Antimicrobial stewardship: what's it all about? Aust Prescr 2013;36:116.20. https://doi.org/10.18773/austprescr.2013.045

6. Australian Commission on Safety and Quality in Health Care. National safety and quality health service standards September 2012. Sydney: ACSQHC; 2012 https://www.safetyandquality.gov.au/publications/nationalsafety-and-quality-health-service-standards [cited 2017 Oct 11]
7. James R. Surgical prophylaxis: data from the Surgical National Antimicrobial Prescribing Survey 2016. Oral presentation at the National Antimicrobial Resistance Forum, Brisbane, 2-3 November 2017. https://cre-reduce.centre.uq.edu. au/event/438/australian-antimicrobial-resistance-forum [cited 2017 Oct 11]

8. Berríos-Torres SI, Umscheid CA, Bratzler DW, Leas B, Stone EC, Kelz RR, et al. Centers for Disease Control and Prevention guideline for the prevention of surgical site infection, 2017. JAMA Surg 2017;152:784-91. https://doi.org/ 10.1001/jamasurg.2017.0904

9. National Institute for Health and Care Excellence. Surgical site infections: prevention and treatment. Clinical guideline 74 . London: NICE; 2008. Updated 2017. www.nice.org.uk/ guidance/cg74

10. Heal CF, Buettner PG, Drobetz H. Risk factors for surgical site infection after dermatological surgery. Int J Dermatol 2012;51:796-803. https://doi.org/10.1111/j.1365-4632.2011.05189.x

11. Smith SC, Heal CF, Buttner PG. Prevention of surgical site infection in lower limb skin lesion excisions with single dose oral antibiotic prophylaxis: a prospective randomised placebo-controlled double-blind trial. BMJ Open 2014;4:e005270. https://doi.org/10.1136/ bmjopen-2014-005270

12. Daly CG. Antibiotic prophylaxis for dental procedures. Aust Prescr 2017;40:184-8. https://doi.org/10.18773/ austprescr.2017.054 
13. Marschall J, Carpenter CR, Fowler S, Trautner BW. Antibiotic prophylaxis for urinary tract infections after removal of urinary catheter: meta-analysis. BMJ 2013;346:f3147. https://doi.org/10.1136/bmj.f3147

14. Bratzler DW, Dellinger EP, Olsen KM, Perl TM, Auwaerter PG, Bolon MK, et al. Clinical practice guidelines for antimicrobial prophylaxis in surgery. Am J Health Syst Pharm 2013;70:195-283. https://doi.org/10.2146/ajhp120568

15. Unger NR, Stein BJ. Effectiveness of pre-operative cefazolin in obese patients. Surg Infect 2014;15:412-6. https://doi.org/ 10.1089/sur.2012.167

16. Ahmadzia HK, Patel EM, Joshi D, Liao C, Witter F, Heine RP, et al. Obstetric surgical site infections: 2 grams compared with 3 grams of cefazolin in morbidly obese women. Obstet Gynecol 2015;126:708-15. https://doi.org/10.1097/ AOG.0000000000001064

17. Ho VP, Nicolau DP, Dakin GF, Pomp A, Rich BS, Towe CW et al. Cefazolin dosing for surgical prophylaxis in morbidly obese patients. Surg Infect (Larchmt) 2012:13:33-7. https://doi.org/10.1089/sur.2010.097

18. Scottish Intercollegiate Guidelines Network. Antibiotic prophylaxis in surgery. SIGN 104. Edinburgh: SIGN; 2008 Updated 2014. http://www.sign.ac.uk/sign-104-antibioticprophylaxis-in-surgery.html [cited 2017 Oct 11]

19. Kessel L, Flesner P, Andresen J, Erngaard D, Tendal B, Hjortdal J. Antibiotic prevention of postcataract endophthalmitis: a systematic review and meta-analysis. Acta Ophthalmol 2015;93:303-17. https://doi.org/10.1111/ aos. 12684

20. Low N, Mueller M, Van Vliet HA, Kapp N. Perioperative antibiotics to prevent infection after first-trimester abortion. Cochrane Database Syst Rev 2012:CD005217. https://doi.org/ 10.1002/14651858.CD005217pub2

21. Glenny AM, Oliver R, Roberts GJ, Hooper L, Worthington HV. Antibiotics for the prophylaxis of bacterial endocarditis in dentistry. Cochrane Database Syst Rev 2013:CD003813. https://doi.org/10.1002/14651858.CD003813.pub4

22. Fry DE. Topical antimicrobials and the open surgical wound. Surg Infect (Larchmt) 2016;17:520-4. https://doi.org/10.1089/ sur.2016.107

23. Levender MM, Davis SA, Kwatra SG, Williford PM, Feldman SR. Use of topical antibiotics as prophylaxis in clean dermatologic procedures. J Am Acad Dermatol 2012;66:445-51.e3. https://doi.org/10.1016/j.jaad.2011.02.005

24. Heal CF, Banks JL, Lepper PD, Kontopantelis E, van Driel ML. Topical antibiotics for preventing surgical site infection in wounds healing by primary intention. Cochrane Database Syst Rev 2016:CD011426. https://doi.org/ 10.1002/14651858.CD011426.pub2

25. Saco M, Howe N, Nathoo R, Cherpelis B. Topical antibiotic prophylaxis for prevention of surgical wound infections from dermatologic procedures: a systematic review and metaanalysis. J Dermatolog Treat 2015;26:151-8. https://doi.org/ 10.3109/09546634.2014.906547

26. Heal CF, Buettner PG, Cruickshank R, Graham D, Browning S, Pendergast J, et al. Does single application of topical chloramphenicol to high risk sutured wounds reduce incidence of wound infection after minor surgery? Prospective randomised placebo controlled double blind trial. BMJ 2009;338:a2812. https://doi.org/10.1136/bmj.a2812

27. Dixon A, Dixon M, Dixon J. Randomized clinical trial of the effect of applying ointment to surgical wounds before occlusive dressing. Br J Surg 2006:93:937-43. https://doi.org/10.1002/bjs.5400
28. Williamson DA, Monecke S, Heffernan $\mathrm{H}$, Ritchie SR, Roberts SA, Upton A, et al. High usage of topical fusidic acid and rapid clonal expansion of fusidic acid-resistant staphylococcus aureus: a cautionary tale. Clin Infect Dis 2014;59:1451-4. https://doi.org/10.1093/cid/ciu658

29. Hetem DJ, Bonten MJ. Clinical relevance of mupirocin resistance in Staphylococcus aureus. J Hosp Infect 2013;85:249-56. https://doi.org/10.1016/j.jhin.2013.09.006

30. Youn SH, Lee SS, Kim S, Lee Ja, Kim BJ, Kim J, et al. Drug utilization review of mupirocin ointment in a Korean university-affiliated hospital. Korean J Intern Med 2015;30:515-20. https://doi.org/10.3904/kjim.2015.30.4.515

31. Hawn MT, Richman JS, Vick CC, Deierhoi RJ, Graham LA, Henderson WG, et al. Timing of surgical antibiotic prophylaxis and the risk of surgical site infection. JAMA Surg 2013;148:649-57. https://doi.org/10.1001/jamasurg.2013.134

32. Steinberg JP, Braun BI, Hellinger WC, Kusek L, Bozikis MR, Bush AJ, et al. Timing of antimicrobial prophylaxis and the risk of surgical site infections. Ann Surg 2009;250:10-6. https://doi.org/10.1097/SLA.0b013e3181ad5fca

33. Anderson DJ, Podgorny K, Beríos-Torres SI, Bratzler DW, Dellinger EP, Greene L, et al. Strategies to prevent surgical site infections in acute care hospitals: 2014 Update. Infect Control Hosp Epidemiol 2014;35:605-27. https://doi.org/10.1086/676022

34. Ban KA, Minei JP, Laronga C, Harbrecht BG, Jensen EH, Fry DE, et al. American College of Surgeons and Surgical Infection Society: surgical site infection guidelines, 2016 Update. J Am Coll Surg 2017;224:59-74. https://doi.org/ 10.1016/j.jamcollsurg.2016.10.029

35. Allegranzi BB, de Jonge S, Kubilay NZ, Zayed B, Gomes SM, Abbas M, et al. New WHO recommendations on preoperative measures for surgical site infection prevention: an evidence-based global perspective. Lancet Infect Dis 2016;16:e276-87. https://doi.org/10.1016/ S1473-3099(16)30398-X

36. Duffield A, Sultan P, Riley ET, Carvalho B. Optimal administration of cefazolin prophylaxis for cesarean delivery. J Perinatol 2017;37:16-20. https://doi.org/10.1038/jp.2016.210

37. Mackeen AD, Packard RE, Ota E, Berghella V, Baxter JK. Timing of intravenous prophylactic antibiotics for preventing postpartum infectious morbidity in women undergoing cesarean delivery. Cochrane Database Syst Rev 2014:CD009516. https://doi.org/10.1002/14651858.CD009516.pub2

38. Lador A, Nasir H, Mansur N, Sharoni E, Biderman P, Leibovici L, et al. Antibiotic prophylaxis in cardiac surgery: systematic review and meta-analysis. J Antimicrob Chemother 2012;67:541-50. https://doi.org/10.1093/jac/dkr470

39. Mertz D, Johnstone J, Loeb M. Does duration of perioperative antibiotic prophylaxis matter in cardiac surgery? A systematic review and meta-analysis. Ann Surg 2011;254:48-54. https://doi.org/10.1097/SLA.0b013e318214b7e4

40. McIntosh J, Earnshaw JJ. Antibiotic prophylaxis for the prevention of infection after major limb amputation. Eur $J$ Vasc Endovasc Surg 2009;37:696-703. https://doi.org/ 10.1016/j.ejvs.2009.01.013

41. Tamma PD, Avdic E, Li DX, Dzintars K, Cosgrove SE. Association of adverse events with antibiotic use in hospitalized patients. JAMA Intern Med 2017;177:1308-15. https://doi.org/10.1001/jamainternmed.2017.1938 